\title{
Urine Matrix Metalloproteinase-3 Level as a Biomarker for Monitoring in Familial Mediterranean Fever Attacks
}

Betul Sozeri ${ }^{1}$, Ebru Yılmaz ${ }^{2}$, Nida Dincel ${ }^{3^{*}}$, Gozde Gozuoglu ${ }^{1}$, Kadriye Ozdemir ${ }^{4}$, Ipek Kaplan Bulut ${ }^{4}$, Hasan Gun $Z^{1}$ and Sevgi Mir ${ }^{4}$

${ }^{1}$ Ege University Medical Faculty, Department of Pediatrics, Turkey

${ }^{2}$ Children Disease and Surgery Training and Research Hospital, Izmir, Turkey

${ }^{3}$ Ankara Children Health and Research Hematology Oncology Education Research Hospital, Ankara, Turkey

${ }^{4}$ Ege University Medical Faculty, Pediatric Nephrology, Turkey

*Corresponding author: Nida Dincel, Ankara Children Health and Research Hematology Oncology Education Research Hospital, Ankara, Turkey, Tel: +90 53058147 99; E-mail: nida_dincel@yahoo.com

Recieved date: March 21, 2013, Accepted date: May 9, 2014, Published date: May 15, 2014

Copyright: (c) 2014 Sozeri B, et al. This is an open-access article distributed under the terms of the Creative Commons Attribution License, which permits unrestricted use, distribution, and reproduction in any medium, provided the original author and source are credited.

\begin{abstract}
Objective: Matrix metalloproteinase-3 (MMP-3) has been implicated in experimental and clinical models of human inflammatory conditions. Increased MMPs levels have been shown in serum and body fluids in inflammatory conditions. Familial Mediterranean Fever (FMF) is an inherited, auto inflammatory disease characterized by recurrent self-limited bouts of fever and localized inflammation. We aimed to investigate whether urine MMP-3 level can serve as a biomarker for monitoring attack in FMF patients in daily practice.
\end{abstract}

Methods: We studied 50 patients diagnosed with FMF according to Tel Hashomer criteria and 32 age-matched healthy controls. We determined all subjects both in attack (FMF-AP) and attack free period (FMF-AFP) groups. Serum and urine samples were obtained within the first $6-24 \mathrm{~h}$ of the AP, and 10 days later after the attack (AFP). The serum samples were measured on the same day while urine samples were frozen immediately and stored at $-80^{\circ} \mathrm{C}$.

Results: The mean age at onset was $57.26 \pm 33.5$ months. The most common symptoms seen during the attacks were: fever ( $80 \%)$ abdominal pain $(72 \%)$, arthritis (40\%). In genotype distribution, homozygous M694V mutation was seen mostly (28\%). During AP, urine MMP-3 levels of patients were higher as well as during AFP and controls $(2.32$ $\pm 0.51,0.89 \pm 2.29 \mathrm{ng} / \mathrm{mL}$ and $1.24 \pm 0.17 \mathrm{ng} / \mathrm{mL}$, respectively, $p=0.00)$. In AP, urinary MMP levels were higher in patients with arthritis than others $(p<0.05)$. Urinary MMP-3 levels were also significantly higher in males $(2.29 \pm 0.45$ versus $2.24 \pm 0.57, p=0,00)$. The patients with M694V allele $(n=29)$ had statistically significant high urine MMP-3 levels than others $(2.37 \pm 0.56$ versus $1.99 \pm 0.31, p=0.04$, respectively). Also, acute phase reactants were higher in patients with M694V allele without statistically significant difference $(p=0.89,0.75,0.86,0.85,0.7$, respectively).

Conclusion: In this study we focused on presence of MMPs in urine and showed inflammation-specific MMP patterns may provide clinicians valuable information in FMF patients.

Keywords: Matrix metalloproteinase-3; Familial mediterranean fever; Biomarker

\section{Objective}

Familial Mediterranean fever (FMF) is an autosomal recessive disease, which predominantly affects certain ethnic groups, mainly Sephardic Jews, Turks, Arabs, and Armenians [1]. FMF is associated with mutations in the gene MEFV encoding pyrin. It is an autoinflammatory disease characterized by recurrent, self-limited attacks of fever and inflammation of serosal surfaces. Pyrin is expressed mainly in neutrophils and macrophages, and modulates the production of the potent pro-inflammatory cytokine interleukin- $1 \beta$ through regulation of nuclear factor- $\kappa \mathrm{B}$ and caspase-1 [2]. Neutrophil degranulation and release of proteases and other cytotoxic mediators can cause tissue damage. Oxygen radicals and matrix metalloproteinases (MMPs), which derived by neutrophils and macrophage, are critical mediators of acute inflammatory tissue damage [3]. MMPs are a family of peptidase enzymes responsible for the degradation of extracellular matrix (ECM), clotting factors, lipoproteins, and cell adhesion molecules [4]. MMP-3 as a key member of metalloproteinase family is involved in the turnover of the number of ECM components also activates some other members of the MMP family [5]. In patients with several inflammatory diseases, MMP levels are elevated in serum and synovial fluid [6-9]. Communication of cells invading joints and blood vessels with the vascular and lymphatic systems might result in increased levels of MMP activity in urine [10]. Two studies in juvenile idiopathic arthritis (JIA) have also shown increased levels of serum MMP-3 compared to controls, and MMP levels correlated with various disease activity indices $[11,12]$

We aim to investigate the relationship between urinary MMP-3 levels and disease activity in patients with FMF and also it can serve as a biomarker for monitoring attack period in daily clinical practice. 


\section{Methods}

Patients were recruited for this study using a protocol that was reviewed and approved by the Institutional Review Board at Ege University Medical Faculty. We studied 50 patients who diagnosed with FMF according to Tel Hashomer criteria and 32 healthy controls. We determine all FMF subjects both in attack period (FMF-AP) and attack free period (FMF-AFP) groups. FMF patients with documented infections such as respiratory tract and urinary tract infections, sepsis, other systemic diseases, and amyloidosis were excluded. Blood and urine samples were obtained within the first 6-24 h of the attack period, and 10 days later after the attack, which was named attack free period. Control group that was matched according to age and sex consisted of completely healthy children without any infection or any other systemic diseases. White blood cell counts (WBC), C-reactive protein (CRP), erythrocyte sedimentation rate (ESR), serum amyloid A protein (SAA), fibrinogen and urine MMP-3 levels were measured in the patients (at two different periods as described above) and control group. The serum samples were measured on the same day while Urine samples were collected on ice and divided into aliquots and frozen immediately and stored at $-80^{\circ} \mathrm{C}$ until ready for assay.

A Beckman Coulter Hematology Analyzer was used for WBC and thrombocyte counts. The ESR was evaluated by the westergren method and $<20 \mathrm{~mm} / \mathrm{h}$ was considered to be normal. The measurement of high-sensitive CRP (hs-CRP) was performed by the nephelometric method (Dade, Behring, Germany) and $<0.35 \mathrm{mg} / \mathrm{dl}$ was accepted as normal.

Urine MMP-3 levels were measured by enzyme-linked immunosorbent assay (ELISA; Invitrogen, Breda, The Netherlands) according to the manufacturer's instructions. The assay measures total human MMP-3 including pro-MMP-3, active MMP-3, and MMP-3 in complex with tissue inhibitor of metalloproteinase (TIMP). We also calculated MMp-3-creatinine ratio.

Statistical analysis: All data were analyzed on SPSS 16.0 (SPSS Inc., Chicago, IL, USA). Results were expressed as mean \pm SD or median (range) for normally distributed and non-normally distributed data, respectively. The independent samples $t$ test and Mann-Whitney $U$ test were used to compare differences between groups. Chi-square test and Fisher exact test were used to compare differences in percentages between groups. Spearman's correlation coefficients were used to analyze the relationship between urine MMP-3 levels and clinical measures of disease activity. $\mathrm{P}$ values $<0.05$ were considered statistically significant.

\section{Results}

The study group comprised 50 FMF patients ( 28 females, 22 males; mean age $8 \pm 3.89$ years) and 38 healthy controls ( 21 females, 17 males; mean age $8.6 \pm 3.76$ years). There were no significant differences between the patients and the control group in terms of age and sex distribution. The mean follow up time was $39.1 \pm 16.3$ months. All patients were already taking colchicine $(0.5-2 \mathrm{mg} /$ day). The mean age at onset of symptoms was $57.26 \pm 33.5$ months. The most common symptom seen during the attacks was: fever $(n=40,80 \%)$ abdominal pain $(n=36,72 \%)$, arthritis $(n=20,40 \%)$ and others (myalgia, erysipelas like lesion, and vasculitis, etc.) $(n=6,12 \%)$.

In the genotype distribution of patients, homozygous M694V mutation was seen mostly $(\mathrm{n}=14,28 \%)$. The remaining patients had M694V/E148Q ( $n=5,10 \%)$, M694V/V726A ( $n=4,8 \%)$, M680I/E148Q $(\mathrm{n}=3,6 \%)$, M694V/M680I $(\mathrm{n}=2,4 \%)$, E148Q/E148Q $(\mathrm{n}=2,4 \%)$, M680I/M680I $(n=2,4 \%)$, M694V/0 $(n=4,8 \%)$, M680I/0 $(n=4,8 \%)$, V726A/0 ( $\mathrm{n}=4,8 \%), \quad$ E148Q/0 $(\mathrm{n}=4,8 \%), \quad \mathrm{K} 695 \mathrm{R} / 0 \quad(\mathrm{n}=2,4 \%)$ mutations.

At the attack period, the mean SAA, CRP, fibrinogen and ESR values were higher than both AFP and normal values in all patients (Table 1).

\begin{tabular}{|l|l|l|l|}
\hline & Attack period & Attack free period & $\mathbf{P}$ \\
\hline WBC $\times \mathbf{1 0}$ 9/L & $8283 \pm 2701$ & $7279 \pm 2197$ & $\mathrm{p}<0.001$ \\
\hline SAA, $\mathbf{m g} / \mathbf{d l}$ & $346 \pm 271$ & $18 \pm 28$ & $\mathrm{p}<0.001$ \\
\hline CRP, $\mathbf{m g} / \mathbf{d l}$ & $8.6 \pm 6.6$ & $0.7 \pm 1.1$ & $\mathrm{p}<0.001$ \\
\hline Fibrinogen, $\mathbf{m g} / \mathbf{d l}$ & $580 \pm 178$ & $287 \pm 100$ & $\mathrm{p}<0.001$ \\
\hline ESR, $\mathbf{m m} / \mathbf{h}$ & $57.3 \pm 32$ & $15 \pm 8$ & $\mathrm{p}<0.001$ \\
\hline
\end{tabular}

Table 1: Laboratory assessments in patients at attack period and attack free period

Abbreviations: WBC: White Blood Cell; SAA: Serum Amyloid A; CRP: C-Reactive Protein; ESR: Erythrocyte Sedimentation Rate

During AP, urine MMP-3 levels of patients were higher as well as during AFP and controls $(2.32 \pm 0.51 \mathrm{ng} / \mathrm{mL}, 0.89 \pm 2.29 \mathrm{ng} / \mathrm{mL}$ and $1.24 \pm 0.17 \mathrm{ng} / \mathrm{mL}$, respectively, $\mathrm{p}=0.00$ ) (Figure 1). The level of urinary MMP-3/ creatinine was detected higher in AP than the AFP and controls (Figure 1). There were no significant differences between the urine MMP3/creatinine ratio of the attack-free periods and healthy control group $(\mathrm{P}=0.28$, Figure 1$)$.

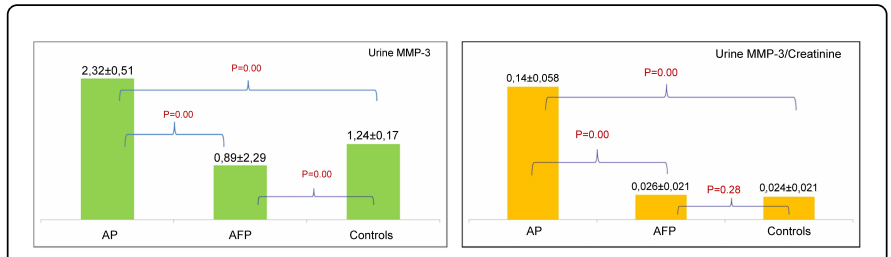

Figure 1: Urine MMP-3 and Urine MMP-3/creatinine levels of the patients and controls

Abbreviations: MMP-3: Matrix metalloproteinase-3

In attack period, urinary MMP levels were detected higher in patients with arthritis than others $(\mathrm{P}<0.05)$ (Table 2). In addition urinary MMP-3 levels were higher in male compared to female patients $(2.29 \pm 0.45$ versus $2.24 \pm 0.57$, respectively, $(\mathrm{P}=0.08)$.

\begin{tabular}{|l|l|l|}
\hline Clinical features & $\begin{array}{l}\text { Urinary MMP3 levels } \\
(\mathrm{ng} / \mathrm{mL})\end{array}$ & $\mathbf{P}$ \\
\hline Fever (presence versus absence) & $2.34 \pm 0.54$ vs. $1.98 \pm 0.23$ & 0.06 \\
\hline $\begin{array}{l}\text { Abdominal pain (presence versus } \\
\text { absence) }\end{array}$ & $2.19 \pm 0.49$ vs. $2.45 \pm 0.52$ & 0.14 \\
\hline Arthritis (presence versus absence) & $2.54 \pm 0.50$ vs. $2.01 \pm 0.37$ & 0.00 \\
\hline
\end{tabular}

Table 2: The MMP levels in urine according to the existing clinical evidence 
Abbreviations: MMP3: Matrix metalloproteinase-3

The patients with M694V allele ( $\mathrm{n}=29$ ) had statistically significant high levels of urine MMP-3 levels and ratio of urinary MMP-3/ creatinine than other patients $(2.37 \pm 0.56$ vs. $1.99 \pm 0.31, \mathrm{P}=0.04$ and
$0.19 \pm 0.1$ vs. $0.11 \pm 0.04, \mathrm{P}=0.02$, respectively, Table 3 ). Also, acute phase reactants (WBC, SAA, fibrinogen CRP, ESR) were higher in patients with $\mathrm{M} 694 \mathrm{~V}$ allele but no there were no statistically significant $(\mathrm{P}=0.89,0.75,0.86,0.85,0.7$, respectively, Table 3$)$.

\begin{tabular}{|l|l|l|l|l|l|l|l|l|}
\hline M694V allele & & WBC & SAA & Fibrinogen & CRP & ESR & Urine MMP-3 & MMP-3/creatinine \\
\hline Presence & Mean & 8386 & 334.8 & 556.16 & 7.54 & 59.33 & 2.37 & 0.19 \\
\hline & SD & 2851 & 239.97 & 209.70 & 6.80 & 28.05 & 0.56 & 0.10 \\
\hline Absent & Mean & 8229 & 384.65 & 536.60 & 6.85 & 53.83 & 1.99 & 0.11 \\
\hline & SD & 2556 & 422.56 & 154.82 & 4.97 & 32.85 & 0.31 & 0.04 \\
\hline P & & 0.89 & 0.75 & 0.86 & 0.85 & 0.7 & 0.04 & 0.02 \\
\hline
\end{tabular}

Table 3: The levels of acute phase reactants and urine MMP-3 in patients with M694V allele in attack period

Abbreviations: MMP3: Matrix metalloproteinase-3; WBC: White Blood Cell; SAA: Serum Amyloid A; CRP: C-Reactive Protein; ESR: Erythrocyte Sedimentation Rate

\section{Discussion}

Familial Mediterranean fever is characterized by recurrent, selflimited episodes of fever and localized inflammation. These episodes of inflammation are mainly mediated by a massive influx of neutrophils into serous cavities and are accompanied by an elevation in the levels of acute-phase inflammatory products and cytokines [13]. There are high serum levels of serum amyloid A (SAA) during active inflammation, particularly during FMF attacks. These markers are increased in $30-90 \%$ of patients with FMF during attack-free periods $[14,15]$.

In this study, we measured the urinary MMP-3 levels in patients with FMF. The urinary MMP-3 levels were found higher at the attack period in patients, than attack free period and controls. Also, the correlation of urinary MMP-3 levels was consistent across multiple disease activity measures, both laboratory and clinically. Our study is the first study showing that urinary MMP-3 is a good marker for disease activity in the FMF.

Inflammatory conditions such as vasculitis and arthritis produce tissue damage by disassembling the complex extracellular matrices delimiting tissue spaces and surrounding blood vessels. MMPs have been implicated in experimental and clinical models of human inflammatory conditions [16]. Firstly, Moses MA et al can be detected in the urine of subjects with a variety of cancers and that these urinary MMPs are predictive of disease status in these subjects [17].

In this study, we found that urinary MMp-3 levels correlated with both SAA and CRP levels in attack period $(r=1.26$ and $r=1.36$, respectively, $\mathrm{p}=0.01)$ and attack free period $(\mathrm{r}=1.16$ and $\mathrm{r}=1.03$, respectively, $\mathrm{p}=0.02$ ). In addition, SAA and CRP measurements were highly correlated in our study $(\mathrm{r}=1.11, \mathrm{p}=0.01)$.

Yoshihara et al. [8] were found which levels of MMP-3 were higher both in synovial fluid and serum in patients with inflammatory arthritis. Recently, high serum levels of MMP -3 in patients with systemic onset juvenile idiopathic arthritis were identified and shown to be associated with the activity of the disease [18]. Another study investigated at MMP levels in serum and synovial fluid of JIA patients and showed some correlation between levels of MMP and disease activity, especially MMP-1 [12]. MMP-3 is produced in the joint by synovial fibroblasts and chondrocytes in an inactive form [19]. Therefore, MMP-3 is a direct effector of cartilage and synovial damage. The maximum MMP3 levels were found in patients presented with arthritis in our cohort (Table 2).

Many studies showed that serum MMPs levels higher in males than females [20]. In addition, Natoli et al. [21] showed that the male sex steroid testosterone increased gene and protein expression of MMP-3. In our cohort, urinary MMP-3 levels were higher in male compared to female patients.

\section{Conclusion}

We have shown urinary MMP-3 levels higher in attack period of FMF and urinary MMP-3 levels have been correlated with acute phase proteins. Clearly urine study is less invasive way of obtaining laboratory data, which is important especially in children. Thus, measuring MMP's in urine could provide a non-invasive means for measuring disease activity in a variety of inflammatory conditions.

\section{References}

1. Sohar E, Gafni J, Pras M, Heller H (1967) Familial Mediterranean fever. A survey of 470 cases and review of the literature. Am J Med 43: 227-253.

2. Grandemange S, Aksentijevich I, Jeru I, Gul A, Touitou I (2011) The regulation of MEFV expression and its role in health and familial Mediterranean fever. Genes Immun 12: 497-503.

3. Warner RL, Bhagavathula N, Nerusu KC, Lateef H, Younkin E, et al. (2004) Matrix metalloproteinases in acute inflammation: induction of MMP-3 and MMP-9 in fibroblasts and epithelial cells following exposure to pro-inflammatory mediators in vitro. Experimental and Molecular Pathology 76:189- 195.

4. Woessner JF Jr (1991) Matrix metalloproteinases and their inhibitors in connective tissue remodeling. FASEB J 5: 2145-2154.

5. Henney AM, Wakeley PR, Davies MJ, Foster K, Hembry R, et al. (1991) Localization of stromelysin gene expression in atherosclerotic plaques by in situ hybridization. Proc Natl Acad Sci U S A 88: 8154-8158.

6. Keyszer G, Lambiri I, Nagel R, Keysser C, Keysser M, et al. (1999) Circulating levels of matrix metalloproteinases MMP-3 and MMP-1, tissue inhibitor of metalloproteinases 1 (TIMP-1), and MMP-1/TIMP-1 complex in rheumatic disease. Correlation with clinical activity of rheumatoid arthritis versus other surrogate markers. J Rheumatol 26: 251-258. 
Citation: Sozeri B, Yilmaz E, Dincel N, Gozuoglu G, Ozdemir K, et al. (2014) Urine Matrix Metalloproteinase-3 Level as a Biomarker for Monitoring in Familial Mediterranean Fever Attacks. J Nephrol Ther 4: 164. doi:10.4172/2161-0959.1000164

Page 4 of 4

7. Taylor DJ, Cheung NT, Dawes PT (1994) Increased serum proMMP-3 in inflammatory arthritides: a potential indicator of synovial inflammatory monokine activity. Ann Rheum Dis 53: 768-772.

8. Yoshihara Y, Obata K, Fujimoto N, Yamashita K, Hayakawa T, et al. (1995) Increased levels of stromelysin-1 and tissue inhibitor of metalloproteinases-1 in sera from patients with rheumatoid arthritis. Arthritis Rheum 38: 969-975.

9. Fiedorczyk M, Klimiuk PA, Sierakowski S, Gindzienska-Sieskiewicz E, Chwiecko J (2006) Serum matrix metalloproteinases and tissue inhibitors of metalloproteinases in patients with early rheumatoid arthritis. J Rheumatol 33: 1523-1529.

10. Nelson AR, Fingleton B, Rothenberg ML, Matrisian LM (2000) Matrix metalloproteinases: biologic activity and clinical implications. J Clin Oncol 18: 1135-1149.

11. Gattorno M, Vignola S, Falcini F, Sabatini F, Buoncompagni A, et al. (2002) Serum and synovial fluid concentrations of matrix metalloproteinases 3 and its tissue inhibitor 1 in juvenile idiopathic arthritides. J Rheumatol 29: 826-831.

12. Peake NJ, Khawaja K, Myers A, Jones D, Cawston TE, et al.( 2005) Levels of matrix metalloproteinase (MMP)-1 in paired sera and synovial fluids of juvenile idiopathic arthritis patients: relationship to inflammatory activity, MMP-3 and tissue inhibitör of metalloproteinases-1 in a longitudinal study. Rheumatology 44:1383-9.

13. Ben-Zvi I, Livneh A (2011) Chronic inflammation in FMF: markers, risk factors, outcomes and therapy. Nat Rev Rheumatol 7: 105-112.

14. Korkmaz C, Ozdogan H, Kasapçopur O, Yazici H (2002) Acute phase response in familial Mediterranean fever. Ann Rheum Dis 61: 79-81.
15. Lachmann HJ, Sengül B, Yavuzşen TU, Booth DR, Booth SE, et al. (2006) Clinical and subclinical inflammation in patients with familial Mediterranean fever and in heterozygous carriers of MEFV mutations. Rheumatology (Oxford) 45: 746-750.

16. Woessner JF (1998) The Matrix Metalloproteinase Family. In: Parks WC, Mecham RP, eds. Matrix Metalloproteinases. San Diego, Calif: Academic Press; 1-13.

17. Moses MA, Wiederschain D, Loughlin KR, Zurakowski D, Lamb CC, et al. (1998) Increased incidence of matrix metalloproteinases in urine of cancer patients. Cancer Res 58: 1395-1399.

18. Sarma PK, Misra R, Aggarwal A (2008) Elevated serum receptor activator of NFkappaB ligand (RANKL), osteoprotegerin (OPG), matrix metalloproteinase (MMP), and ProMMP1 in patients with juvenile idiopathic arthritis. Clin Rheumatol 27: 289-294.

19. Nagase H, Woessner JF Jr (1999) Matrix metalloproteinases. J Biol Chem 274: 21491-21494.

20. Arends S, van der Veer E, Groen H, Houtman PM, Jansen TL, et al. (2011) Serum MMP-3 level as a biomarker for monitoring and predicting response to etanercept treatment in ankylosing spondylitis. J Rheumatol 38: $1644-1650$

21. Natoli AK, Medley TL, Ahimastos AA, Drew BG, Thearle DJ, et al. (2005) Sex steroids modulate human aortic smooth muscle cell matrix protein deposition and matrix metalloproteinase expression. Hypertension 46: 1129-1134. 